\title{
The Future of Ex-Ante LCA? Lessons Learned and Practical Recommendations
}

\author{
Matthias Buyle ${ }^{1,2, *(\mathbb{D}}$, Amaryllis Audenaert ${ }^{1}$, Pieter Billen ${ }^{3}{ }^{\circledR}$, Katrien Boonen ${ }^{2}$ and \\ Steven Van Passel 4 (D) \\ 1 Energy and Materials in Infrastructure and Buildings (EMIB), University of Antwerp, 2020 Antwerp, Belgium \\ 2 Unit Sustainable Materials Management, Flemish Institute for Technological Research (VITO), 2400 Mol, Belgium \\ 3 Biochemical Green Engineering \& Materials (BioGEM), University of Antwerp, 2020 Antwerp, Belgium \\ 4 Department of Engineering Management, University of Antwerp, 2000 Antwerp, Belgium \\ * Correspondence: matthias.buyle@uantwerpen.be
}

Received: 28 August 2019; Accepted: 24 September 2019; Published: 1 October 2019

check for updates

\begin{abstract}
Every decision-oriented life cycle assessment (LCAs) entails, at least to some extent, a future-oriented feature. However, apart from the ex-ante LCAs, the majority of LCA studies are retrospective in nature and do not explicitly account for possible future effects. In this review a generic theoretical framework is proposed as a guideline for ex-ante LCA. This framework includes the entire technology life cycle, from the early design phase up to continuous improvements of mature technologies, including their market penetration. The compatibility with commonly applied system models yields an additional aspect of the framework. Practical methods and procedures are categorised, based on how they incorporate future-oriented features in LCA. The results indicate that most of the ex-ante LCAs focus on emerging technologies that have already gone through some research cycles within narrowly defined system boundaries. There is a lack of attention given to technologies that are at a very early development stage, when all options are still open and can be explored at a low cost. It is also acknowledged that technological learning impacts the financial and environmental performance of mature production systems. Once technologies are entering the market, shifts in market composition can lead to substantial changes in environmental performance.
\end{abstract}

Keywords: ex-ante life cycle assessment; emerging technology; technological learning; technology diffusion; review; case study; theoretical framework

\section{Introduction}

The purpose of life cycle assessment (LCA) can differ across studies, but in most cases the target is to provide information for decision support, aimed at the achievement of a more sustainable society [1,2]. Once a decision is made, its implementation requires time and the outcomes will only be evident in the future. Therefore, all decision-oriented LCAs entail, at least to some extent, a future-oriented feature. Nonetheless, to date, the majority of the LCA studies are retrospective in nature and do not explore possible future effects explicitly. A key assumption in this case is that historical trends can be considered as representative for forthcoming situations. But in reality, development is often a non-linear process, including both continuous improvements and disruptive changes. Incorporating a more nuanced analysis of expected future developments in LCA can therefore be essential. Such future-oriented LCAs, referred to as ex-ante LCAs in this review, have received little attention so far.

There are exceptions though: some studies are anticipating possible future states given the rationale that today's technology performance is not always suitable for assessing future technologies [3]. Typically, such technologies are in an early stage of development, known as emerging technologies, and they are not ready to enter the market yet. Depending on their technology readiness, they 
may exist as an industrial pilot, in a lab environment, as a proof-of-concept based on preliminary simulations or even only as a basic idea. Multiple research cycles still have to be run through before such technologies can become available at an industrial scale. Integrating LCA early-on in the technology development process can improve the understanding of the implications of design choices on the environmental performance of a technology [4]. This is desirable, as such decisions can have a far-reaching influence on the future success of a technology, because they can prevent environmental burdens and unsound investments at a low cost [5]. In fact, the earlier LCA results can be integrated, the better. A drawback is that only limited data and knowledge on the technology under development is available at this stage. This is also known as the design paradox or Collingridge dilemma [6]. Moreover, the final goal of an LCA of technologies under development should not be the assessment of the environmental performance of emerging technologies at a lab or pilot scale, but to achieve this for the potential future technology at an industrial scale. An ex-ante approach is indispensable as well for a legitimate comparison of emerging technologies with their more mature counterparts. So, a first relevant application of ex-ante LCA consists of assessing technologies at an early stage of development. Ex-ante LCA can be used (1) to estimate the environmental profile of an emerging technology on an industrial scale and use this information to steer further research efforts and (2) to compare an emerging technology with an incumbent technology on an industrial scale.

The benefits of anticipating future situations are evident and-at least from a conceptual point of view-generally acknowledged in the case of emerging technologies [4,7]. However, the concept of ex-ante LCA should not be limited to emerging technologies. Two other applications of ex-ante LCA are worth mentioning. First, all technologies and product systems evolve over time, even if they are mature and abundantly available on an industrial scale for quite some time. It is well-known that technological learning influences both the economic and environmental performance of production systems. For example, the concept of learning (or experience) curves has been developed in order to link empirically observed cost reductions of a technology to key factors such as the cumulative production volume or the installed capacity [8]. If such cost reductions are triggered by an increase in energy efficiency and/or by an optimised material management, it is likely that these factors will improve the environmental performance as well. More formally, technological learning can be described as a development due to an increase in knowledge that comes from more experience [8]. Second, once a new technology or product system is launched commercially, its market penetration determines the magnitude of the environmental consequences in the total market mix [9]. This is also known as technology diffusion, an analysis of the way and the rate that new products, services and ideas spread [10]. For example, renewable energy technologies are typically considered as a more environmentally sound alternative for fossil fuels, yet for the time being their potential benefits are limited by their low market share [11].

The previous three applications, i.e., technology development, technological learning and technology diffusion, are relevant for the technology or production system under study, which is also known as the foreground system. Yet, the same logic applies to the entire economic system as well, often referred to as the background system. This yields a fourth application of ex-ante LCA: all background processes ought to be updated systemically when future states are explored $[7,12]$. For example, developments in the electricity sector can have a substantial effect on the environmental profile of an emerging technology that appears to be energy intensive [13].

Despite the growing awareness of the importance of incorporating possible future evolutions in LCA, the current implementation of ex-ante LCA is still rather limited and non-uniform. This non-uniformity has resulted in the creation of a variety of definitions, concepts, approaches and procedures, each of them targeting different future-oriented aspects. Therefore, the aim of this study is (1) to clarify current definitions, terminology and concepts related to ex-ante LCA, (2) to develop a generic theoretical framework that fits all four relevant applications of ex-ante LCA, (3) to categorise practical methods and procedures on how to incorporate future-oriented features in LCA, based on a broad selection of case studies, and discuss their position within the framework, and finally (4) to 
highlight some limitations and research opportunities. This study builds on and updates prior research efforts of Arvidsson et al. [7] and Cucurachi et al. [4]. However, a more comprehensive review was necessary to go beyond the analysis of emerging technologies only.

The main focus of this review is to identify the existing methods and concepts that include the effect of technological and socio-economic changes in LCA. In this context, the three most relevant steps as defined in the ISO 14040 series $[14,15]$ are: a goal and scope definition, a life cycle inventory (LCI) and an interpretation. A detailed analysis of the life cycle impact assessment (LCIA) step is beyond the scope of this review. Yet, for the impact assessment, two important topics can be observed in an ex-ante context, namely the time-dependent evaluation of the assessed environmental performance [16] and the lack of required data or relevant impact categories in case disruptive emerging technologies are to be assessed, e.g., data on toxicity for nanotechnology [17]. More information about these topics can be found in $[18,19]$.

\section{Methods}

\subsection{Taxonomy}

Over the years, many names for several modes of LCA have been coined, such as attributional LCA (ALCA), backcasting LCA (BLCA), consequential LCA (CLCA), dynamic LCA (DLCA), environmental LCA (ELCA), etc., [20]. Some of these modes have seen their names changed over the years, which has probably increased confusion. One of the most persistent debates in the LCA community is about attributional and consequential LCA [21]. In the early days, consequential LCA was sometimes referred to as prospective LCA, despite the fact that both a retrospective and a prospective consequential modelling approach are possible [22]. The former assesses observed changes following a prior decision, while the latter aims at exploring how a current decision will change future flows. Still, to date, some studies define themselves as prospective LCAs when they mean to say they follow a consequential modelling approach $[23,24]$. A similar reasoning applies to dynamic LCA, a mode of LCA that is often associated with future states as well. The latter are studies "in which the temporal dimension is taken into account in one way or another" [25]. Such studies are not future-oriented by definition, since both empirically observed evolutions as well as expected temporal effects can be considered.

For modes of LCA that do account explicitly for possible future states, the terminology is also far from homogeneous. First, a prospective LCA aims at exploring potential future life cycle environmental impacts, typically using scenarios [26-28]. Second, an anticipatory LCA is defined by Wender et al. as "a forward-looking, non-predictive tool that increases model uncertainty through inclusion of prospective modelling tools and multiple social perspectives" [26]. The difference, they state, is that now stakeholder values and/or multiple social perspectives are to be included in order to achieve responsible research and innovation, while this is not a prerequisite for the aforementioned prospective LCA. However, many studies that define themselves as prospective LCA do include multiple socio-economic perspectives too $[12,27,29]$. A third mode is ex-ante LCA which "explores the future by assessing a range of possible scenarios that define the space in which the technology may operate" [4]. But Cucurachi et al. [4] put forward a narrower definition, based on the application of the study in question. They considered an LCA to be ex-ante only when the upscaling of an emerging technology was assessed or when an emerging technology was compared with the evolved incumbent technology at an industrial scale. Note that the definition of the term emerging technology is subject to a similar ambiguity as the taxonomy in LCA. It is used for technologies that have entered the market recently, technologies of which the market share is increasing rapidly [30], as well as for technologies that are still under development and are not ready yet to enter the market [31]. In this review, the last interpretation was adopted. A more detailed discussion can be found in [32].

So, subtle but not consistent differences can be found between prospective, anticipatory and ex-ante LCAs, mainly related to whether a social perspective is included or not. This review aims at including as many relevant approaches, methods and techniques to explore and incorporate possible 
future states in LCA as possible. Therefore, the broadest interpretation is adopted and all these types of modes will be referred to as ex-ante LCA in this study. The term prospective LCA is not used, so as to avoid confusion with the early definition of consequential LCA.

\subsection{Case Study Selection and Evaluation}

In order to develop a generic theoretical framework that is able to incorporate the four applications identified in the first section, both case studies and review papers were analysed. Fifty-two case studies that define themselves as ex-ante, prospective or anticipatory LCA, complemented with LCA studies that focus on technological change, were selected. Web of Science was used as bibliographic database. After a first screening on the keywords 'ex-ante LCA', 'prospective LCA' and 'anticipatory LCA' only case studies targeting the broad domain of environmental assessments were retained for further analysis. Additionally, thirteen review papers were screened, together with a smaller number of studies that analyse technological learning and technology diffusion. In the latter case, only highly cited papers were included, given their importance in their respective research domains. Incorporating technological learning and technology diffusion in LCA is currently still in its infancy, and although the reviewed studies do not always have a direct link with LCA, they highlight interesting research opportunities.

Based on an initial screening, the following criteria are therefore selected to classify and evaluate the case studies. A first criterion is the level of technological maturity of the studied subjects. Two commonly used scales for estimating this technology maturity are the technology readiness level (TRL) scale and the manufacturing readiness level (MRL) scale [33]. The first scale focuses on functional readiness, while the second includes the maturity of components or subsystems from a manufacturing perspective as well. Both scales can be directly linked, since technology readiness is a prerequisite for manufacturing readiness [34]. The TRL scale is a more widely applied system and will be used in this study. Once a technology or a production system has entered the market, further developments and optimisations will take place, due to learning-by-doing and learning-by-researching. To facilitate comparison with technologies under development, technologies available on the market are assigned a TRL of $9+$ to emphasise their continuous improvements.

The second criterion relates to whether changes in the foreground and/or background system are taken into account. In this review, the 'management' perspective on foreground and background systems of the ILCD handbook is applied, which focuses on whether processes can be directly controlled or influenced by the decision-maker [1]. The foreground system can be directly affected, the background system cannot. The analysis of feedback loops from the foreground to the background system is an extension of the second criterion.

The rationale of the system model forms the third criterion. In short, this can be summarised as the choice between an attributional and a consequential modelling approach.

And finally, the exact modelling techniques of how technological changes and future states are explored are the fourth criterion. These techniques are subdivided into three subcategories: technology development (TRL < 9), technological learning (TRL 9+) and technology diffusion (TRL 9+).

Please note that this review will examine the case studies from a methodological point of view, in order to gain insight into how future states are to be explored and to better understand the current state-of-the-art of ex-ante LCA. It is important to note that this analysis is by no means a judgement on the overall quality or the relevance of the reviewed case studies.

\section{Results}

This section starts with a description of the proposed framework (see Figure 1). Before zooming in on the specific characteristics of the individual case studies and on how they fit into the framework, some important observations on ex-ante LCA in general are presented first. Afterwards, the specific procedures, techniques to collect data and concepts are discussed in detail per subcategory (technology development, technological learning and technology diffusion). If techniques can be classified into 
several subcategories, they will be discussed only the first time they appear in the framework. An overview of all techniques and their application areas is shown in Figure 2.

\subsection{Framework for Ex-Ante LCA}

The reviewed case studies have very diverse properties. Therefore, a generic framework is proposed to create some structure in this whole (see Figure 1). The general goal of this framework is to study a technology, from the formulation of its initial idea up to the point where it can be considered as a new incumbent technology. Three technology related subcategories are included (technology development, technological learning and technology diffusion), as well as one methodological aspect (the selection of the system model). The three technology-related aspects can be applied to all technological evolutions over time, whether they occur in the foreground or the background system. However, modelling emerging technologies in the foreground system versus learning effects of a mature technology in the background system requires a different approach and/or a different level of detail. Thus, a distinction has to be made between the methods used in the foreground system, that includes emerging technologies and mature technologies serving as a reference for comparison, and the background system, as defined in Section 2.2. Additionally, three points of time are set: $t_{0}$ stands for the current situation, $t_{1}$ for the moment when the emerging technology reaches maturity and is ready to enter the market and $t_{2}$ for a point further in the future when the technology has been implemented for a while. For the sake of simplicity, only three points of time are included in Figure 1. Of course, the temporal resolution can be increased to make an assessment more dynamic if necessary.

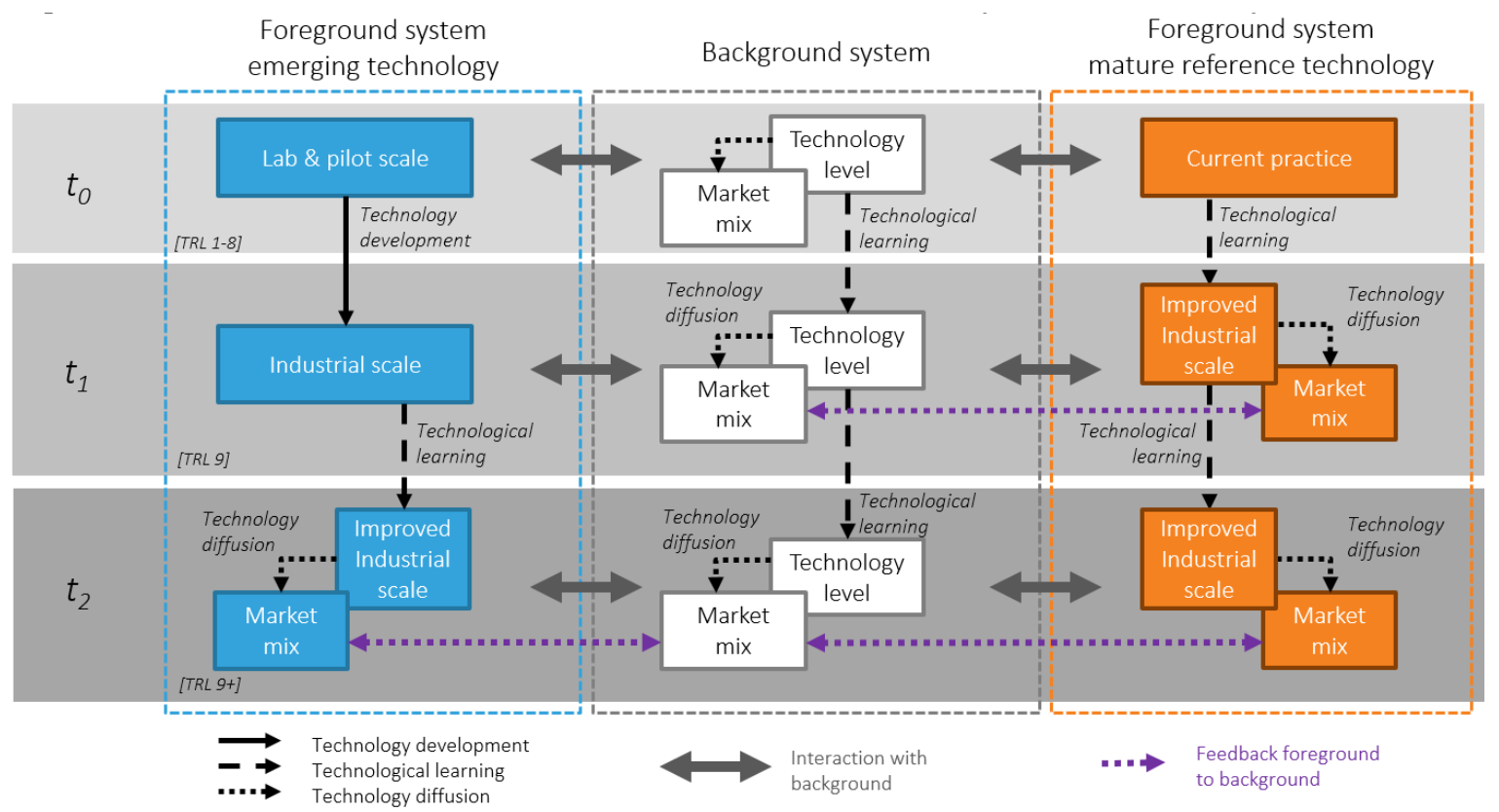

Figure 1. General framework for ex-ante life cycle assessment (LCA). Blue dashed box: evolution of the technology under study (foreground system), orange dashed box: evolution of a mature reference or incumbent technology (foreground system), grey dashed box: changes in the background system. Note: changes in the background system may be disruptive as well, but for the sake of the readability of the figure, this is not shown explicitly.

In the case of the emerging technologies (shown on the left in Figure 1), the first step concerns technological development in the stage where the technology is not yet commercially available. Exploring and estimating how a technology could operate at an industrial scale at time $t_{1}$ is the central issue. After a technology is introduced into the market, it still improves by means of learning-by-doing and learning-by-researching. Also, it can be expected that its market share will increase. It is therefore relevant to estimate the technological changes and the market share at time $t_{2}$ in order to compute its 
contribution to the average or marginal technology mix. The same reasoning applies to technologies that are already mature at $t_{0}$, such as the reference technologies and the background system. The only difference here is that the main changes come from technological learning and changes in technology diffusion, which should be estimated both at times $t_{1}$ and $t_{2}$. In the ideal case, all the different analysed parts can be linked, in the sense that current emerging technologies and/or improved mature technologies can be integrated in the future background system at $t_{1}$ and $t_{2}$. Note that evolutions in the background system may include disruptive changes as well, but for the sake of the readability of the figure, this is not shown explicitly.

As stated in Section 2.1, an ex-ante LCA of emerging technologies can have two goals: to streamline technology development in an environmentally sound way and/or to compare a scaled up emerging technology with an incumbent counterpart as a reference. In Figure 1 the second possibility is shown, with the incumbent technology on the right-hand side (in orange). Of course, this reference technology can be excluded in the first possibility, where the focus is on technology development. Moreover, the use of this framework is not solely limited to the assessment of emerging technologies. In fact, it could be used for all studies with some future-oriented feature: just exclude $t_{0}$, let $t_{1}$ represent the current state-of-play and choose for $t_{2}$ a point down the line, depending on the temporal scope of the study. In other words, in this case, a mature reference technology is considered as the technology under study.

The previous paragraphs have focused on changes of the assessed technologies and production systems. In addition to the three technology-related aspects of the framework, there is a fourth one: the selection of the system model. Various philosophies exist, and they differ mainly in the assumptions they make about which suppliers or processes will be affected by a change in demand. An advantage of the proposed framework is that it fits all approaches, including the two most discussed in the literature, i.e., attributional and consequential LCA.

In the following sections, some general observations will be presented first. Then the techniques to quantify the different components of the framework will be identified and discussed more in detail, based on the input from the reviewed case studies (see Table 1). There is a wide variety of approaches for modelling technological changes, ranging from very detailed technical procedures to a more conceptual explorative development of storylines. To facilitate the examination of their advantages and disadvantages, the approaches are categorised as concept, procedure and technique for data collection. This categorisation depends on the field of application and type of output per approach. Concepts reflect a way of thinking about what is possible and/or likely to happen. Procedures are more a technical and delimited set of actions on how to model technological progress. Data collection is about gathering the required input data. An overview of the identified methods and for which TRLs they can be used is shown in Figure 2. It should be noted that a method can occur in more than one subcategory. For example, Caduff et al. use power laws based on empirically observed scaling relationships to scale windmills [35] and heating devices [36] which are both mature products, while similar approaches are applied to model the scale up from lab to industrial size $[37,38]$. Also, often several methods are combined per study. For example, one method is collecting data that are used as input for a scaling method, in combination with socio-economic storylines. 
Table 1. Summary of properties review case studies.

\begin{tabular}{|c|c|c|c|c|c|c|c|c|c|c|c|c|c|c|c|c|c|c|c|c|c|}
\hline \multirow{2}{*}{ Author(s) } & \multirow{2}{*}{ Topic } & \multirow{2}{*}{ TRL $^{1}$} & \multirow{2}{*}{$\begin{array}{l}\text { Changes } \\
\text { FG }\left(\Delta_{\mathrm{FG}}\right)\end{array}$} & \multirow{2}{*}{$\begin{array}{l}\text { Changes } \\
\text { BG }\left(\Delta_{\mathrm{BG}}\right)\end{array}$} & \multirow{2}{*}{$\begin{array}{c}\text { Feed-back } \\
\text { FG-BG }\end{array}$} & \multirow{2}{*}{$\begin{array}{l}\text { System } \\
\text { Model }\end{array}$} & \multicolumn{6}{|c|}{ Technology Development } & \multicolumn{5}{|c|}{ Technological Learning } & \multicolumn{4}{|c|}{ Technology Diffusion } \\
\hline & & & & & & & $I S B$ & PSS & $P T T_{\mathrm{p}}$ & $P T T_{\mathrm{i}}$ & $S E E$ & $P M$ & SEE & $P M$ & $L C$ & $e a L C$ & SES & $P M$ & SES & ICC & $D A$ \\
\hline Arvidsson and Molander [39] & Graphene production & $3-4$ & + & $-1+$ & - & ALCA & - & - & + & - & - & + & - & - & - & - & - & - & - & - & - \\
\hline Aryapratama and Janssen [40] & Adipic acid production & $3-4$ & $-1+$ & - & - & ALCA & - & - & - & - & - & $-1+$ & - & - & - & - & - & - & - & - & - \\
\hline Bauer et al. [41] & Passenger vehicles & $9+$ & + & + & - & ALCA & - & - & - & - & - & - & + & + & $-/+$ & - & + & + & + & - & - \\
\hline Beltran et al. [12] & Electric vehicles & $9+$ & & + & - & ALCA & - & - & - & - & - & - & + & + & + & - & + & + & + & - & - \\
\hline Bergesen and Suh [42] & CdTe PV panels & $9+$ & $-1+$ & + & - & ALCA & - & - & - & - & - & - & + & + & + & - & - & - & - & - & - \\
\hline Blok et al. [43] & $\begin{array}{l}\text { Nanotecchnology, smartphones, } \\
\text { energy production, paint }\end{array}$ & - & + & + & - & n.s. & - & $-/+$ & - & - & + & + & - & - & - & - & - & + & + & $-1+$ & ! \\
\hline Buyle et al. [44] & Construction products & $9+$ & $-1+$ & $-1+$ & - & h-CLCA & - & - & - & - & - & - & - & - & - & - & - & + & + & $-/+$ & - \\
\hline Caduff et al. [36] & Heat pumps and biomass furnaces & $9+$ & + & - & - & ALCA & - & - & - & $-/+$ & - & - & + & + & - & - & - & - & - & - & - \\
\hline Caduff et al. [35] & Wind turbines & $9+$ & + & - & - & ALCA & - & - & - & - & + & + & + & - & - & - & - & - & - & - & - \\
\hline Chen et al. $[23,45]$ & Hydrogen production & $4-5$ & 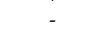 & + & - & h-CLCA & - & - & - & - & - & - & 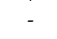 & - & - & - & - & + & - & - & - \\
\hline Cox et al. [46] & Electric vehicles & $9+$ & + & + & - & ALCA & - & - & - & - & + & + & + & + & - & - & + & - & - & - & - \\
\hline Delgado-Aguilar et al. [47] & Nanocellulose-enforced paper & $3-4$ & + & $-1+$ & - & ALCA & - & - & - & - & + & - & - & - & - & - & - & - & - & - & - \\
\hline Dick et al. [48] & Structural elements and engines & $9+$ & $-1+$ & - & - & ALCA & - & - & + & - & - & - & 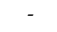 & - & - & - & - & - & 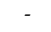 & - & - \\
\hline Garcia-Gusano et al. [49] & Electricity production & $9+$ & + & - & - & eq-CLCA & - & - & - & - & - & - & + & - & - & - & - & - & + & - & + \\
\hline Gavankar et al. [33] & Carbon nanotubes & $7-8$ & + & - & - & ALCA & - & - & - & $-/+$ & - & + & . & - & - & - & - & - & - & - & - \\
\hline Gibon et al. [50] & Concentrating solar power & $9+$ & + & + & + & ALCA & - & - & - & - & + & + & - & + & - & + & + & + & + & - & - \\
\hline Healy et al. [51] & Carbon nanotubes & $3-4$ & + & - & - & ALCA & - & - & - & - & + & + & - & - & - & - & - & - & - & - & - \\
\hline Hospido et al. [52] & Food products & - & + & - & - & ALCA & - & - & - & - & - & $!$ & - & - & $!$ & - & - & - & - & - & - \\
\hline Hung et al. [53] & Screening framework & & $-1+$ & - & - & & - & - & - & - & $!$ & $-1+$ & ! & - & - & - & - & - & - & - & $!$ \\
\hline $\begin{array}{l}\text { Janssen et al. [54] } \\
\text { Käthën }\end{array}$ & Ethanol production from wheat straw & $3-4$ & + & i & - & ALCA & - & - & - & - & + & - & - & - & - & - & - & - & - & - & - \\
\hline $\begin{array}{l}\text { Katelhön et al. [55] } \\
\text { Ky }\end{array}$ & $\begin{array}{l}\text { Chlor-alkali electrolysis } \\
\text { Fullerene and carbon nanot }\end{array}$ & $3-4$ & - & + & - & h-CLCA & - & - & - & - & - & - & - & - & - & - & - & - & - & + & - \\
\hline $\begin{array}{l}\text { Kushnir and Sandén n } 56] \\
\text { Liptow et al. [57] }\end{array}$ & $\begin{array}{l}\text { Fullerene and carbon nanotubes } \\
\text { Ethlene production from wood }\end{array}$ & $\begin{array}{l}3-4 \\
7-8\end{array}$ & ${ }_{+}^{+}$ & - & - & ALCA & + & - & i & - & + & + & - & - & - & - & - & - & - & - & - \\
\hline $\begin{array}{l}\text { Liptow et al. } 57 \text { [ } \\
\text { Manda et al. [58] }\end{array}$ & $\begin{array}{l}\text { Ethylene production from wood } \\
\text { Membrane filtration system }\end{array}$ & $\begin{array}{l}7-8 \\
3-4\end{array}$ & ${ }^{+}$ & 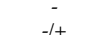 & - & ALCA & 5 & - & + & $-\overline{-i}$ & + & + & - & 5 & - & - & - & - & - & - & - \\
\hline $\begin{array}{l}\text { Manda et al. [58] } \\
\text { Manda et al. [59] }\end{array}$ & $\begin{array}{l}\text { Membranee filtratton system } \\
\text { Antibacterial T-shirt }\end{array}$ & $\begin{array}{c}3-4 \\
5\end{array}$ & $\begin{array}{l}+ \\
+\end{array}$ & ${ }^{-1+}$ & - & $\begin{array}{l}\text { ALCA } \\
\text { ALCA }\end{array}$ & - & 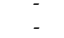 & - & $\begin{array}{c}-1+ \\
-1+\end{array}$ & - & $\begin{array}{l}+ \\
+\end{array}$ & - & - & - & - & - & - & - & - & - \\
\hline Menten et al. [11] & Energy system & $9+$ & + & + & - & eq-CLCA & - & - & - & - & - & - & - & - & + & - & - & - & + & + & - \\
\hline Muñoz et al. [24] & Wastewater treatment & 5 & + & - & - & $\mathrm{h}$-CLCA & - & - & + & - & + & + & - & - & - & - & - & - & 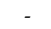 & & - \\
\hline Nordelöf [38] & Power electronic inverter & $9+$ & + & - & - & LCI only & - & - & - & - & + & + & - & - & - & - & - & - & - & - & - \\
\hline Nordelöf et al. [37] & Power electronic inverter & $9+$ & + & - & - & LCI only & - & - & - & - & + & + & - & - & - & - & - & - & - & & - \\
\hline O'Brien et al. [60] & agriculture & $9+$ & + & - & - & ALCA & - & - & - & - & - & - & + & + & - & - & - & - & & + & - \\
\hline Patel et al. [61] & But-1,3-diene & $3-4$ & + & - & - & ALCA & - & - & - & - & - & - & - & - & - & - & - & - & - & - & - \\
\hline Pehnt [62] & Renewable energy technologies & $9+$ & + & + & - & ALCA & - & - & - & - & + & $-/+$ & + & $-1+$ & - & - & - & - & - & + & - \\
\hline Piccinno et al. [63] & Liquid phase batch reactions & $3-4$ & + & - & - & n.s. & + & - & + & - & + & + & - & - & - & - & - & - & - & - & - \\
\hline Pini et al & Self-cleaning coated float glass & $4-5$ & + & - & - & $\mathrm{AL}$ & - & - & - & - & + & + & - & - & - & - & - & - & - & - & - \\
\hline Ravikumar et al. [65] & 1. pares & $9+$ & $-1+$ & - & - & $\mathrm{AL}$ & - & - & - & - & - & $-/+$ & - & - & - & - & - & - & - & - & - \\
\hline Ravikun & Recycling & $9+$ & $-1+$ & - & - & ALC & - & - & - & - & - & - & - & - & - & - & - & - & - & - & - \\
\hline Roes and Patel [ & Caprolactam pr & 2 & + & - & - & ALC & + & - & - & - & + & + & - & - & - & - & - & - & - & - & - \\
\hline Shibasaki et al. [68] & $\begin{array}{l}\text { Scale up of a generic plant } \\
\text { SCle un }\end{array}$ & $\begin{array}{l}6-7 \\
7-8\end{array}$ & + & $-\overline{-}+$ & : & ALC & - & - & - & - & + & - & - & - & - & - & - & - & - & - & - \\
\hline $\begin{array}{l}\text { Shibasaki et al. [60] } \\
\text { Simon et al. [70] }\end{array}$ & $\begin{array}{l}\text { Scale up of a generic plant } \\
\text { LPF-CnF batterie }\end{array}$ & $7-8$ & + & $-1+$ & - & ALCA & - & - & - & - & + & - & - & - & - & - & - & - & - & - & - \\
\hline $\begin{array}{l}\text { Simon et al. } \text {. } 70] \\
\text { Spielmann et al. [29] }\end{array}$ & $\begin{array}{l}\text { LFP--CnF batteries } \\
\text { Transport systems }\end{array}$ & $\begin{array}{l}3-4 \\
9+\end{array}$ & $\begin{array}{l}+ \\
+\end{array}$ & $\begin{array}{c}- \\
+\end{array}$ & - & $\begin{array}{l}\text { ALCA } \\
\text { ALCA }\end{array}$ & - & :- & \pm & - & + & + & $i$ & 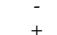 & - & - & - & $\dot{+}$ & $\dot{+}$ & - & - \\
\hline $\begin{array}{l}\text { Spieimannn et al. } \\
\text { Tan et al. [17] }\end{array}$ & $\begin{array}{l}\text { Iransiorors systems } \\
\text { Cellulose nanocrystal foam }\end{array}$ & 3 and 4 & $\begin{array}{l}+ \\
+\end{array}$ & 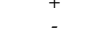 & - & $\begin{array}{l}\text { ALAA } \\
\text { ALCA }\end{array}$ & - & $-1+$ & - & :- & - & + & - & $\stackrel{+}{-}$ & - & - & - & $\stackrel{+}{-}$ & + & - & - \\
\hline Tecchio et al. [71] & Bio-based plastics & 3 & + & - & - & ALCA & + & - & - & + & - & - & - & - & - & - & - & - & - & - & - \\
\hline Van der Voet et al. [72] & Metals & $9+$ & + & + & - & ALCA & - & - & - & - & - & - & + & + & - & - & + & - & + & - & - \\
\hline Vandepaer et al. [73] & Electricit & 9 & - & + & - & h-CLCA & - & - & - & - & - & - & - & - & - & - & - & + & + & $-1+$ & - \\
\hline $\mathrm{Vi}$ & Metal 1 & $2-2$ & + & $-1+$ & - & $\mathrm{AL}$ & - & - & + & - & + & + & - & - & - & - & - & - & - & - & - \\
\hline $\mathrm{Vi}$ & Metal re & $x^{2-3}$ & + & $-1+$ & - & & - & ! & + & - & + & + & - & - & - & - & - & - & - & - & - \\
\hline$w$ & Nanos & $3-4$ and $6-7$ & + & - & - & & - & - & - & - & - & + & - & - & - & - & - & + & + & - & - \\
\hline Wender et al. I & DI & $9+$ & + & - & - & & + & $-/+$ & - & - & - & + & - & - & $!$ & - & - & + & - & - & - \\
\hline $\begin{array}{l}\text { Yao et al. [77] } \\
\text { Zimmermann et al. [78] }\end{array}$ & $\begin{array}{l}\text { Ethylene production } \\
\text { Electric vehicles }\end{array}$ & $\begin{array}{l}4-6 \\
9+\end{array}$ & - & $\stackrel{+}{+}$ & : & $\begin{array}{l}\text { ALCA } \\
\text { ALCA }\end{array}$ & - & : & : & - & - & - & : & $\overline{+}$ & - & - & - & \pm & + & - & - \\
\hline
\end{tabular}

${ }^{1}$ The TRL level is not specified in most of the studies. A range of possible levels is used when the exact level is undefinable. - = not included, $/+=$ partially included, $+=$ included, $!=$

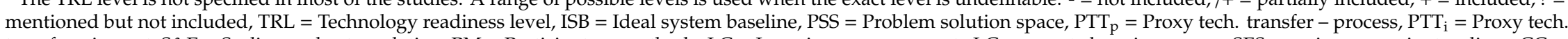
transfer - impact, $\mathrm{S} \& E=$ Scaling and extrapolation, $\mathrm{PM}=$ Participatory methods, $\mathrm{LC}=$ Learning curves, ex-ante LC $=$ ex-ante learning curves, $\mathrm{SES}=$ socio-economic storylines, CC $=$ Cost-curves, DA = diffusion analysis, ALCA = attributional LCA, h-CLCA = heuristic consequential LCA, eq-CLCA = equilibrium model-based consequential LCA. 


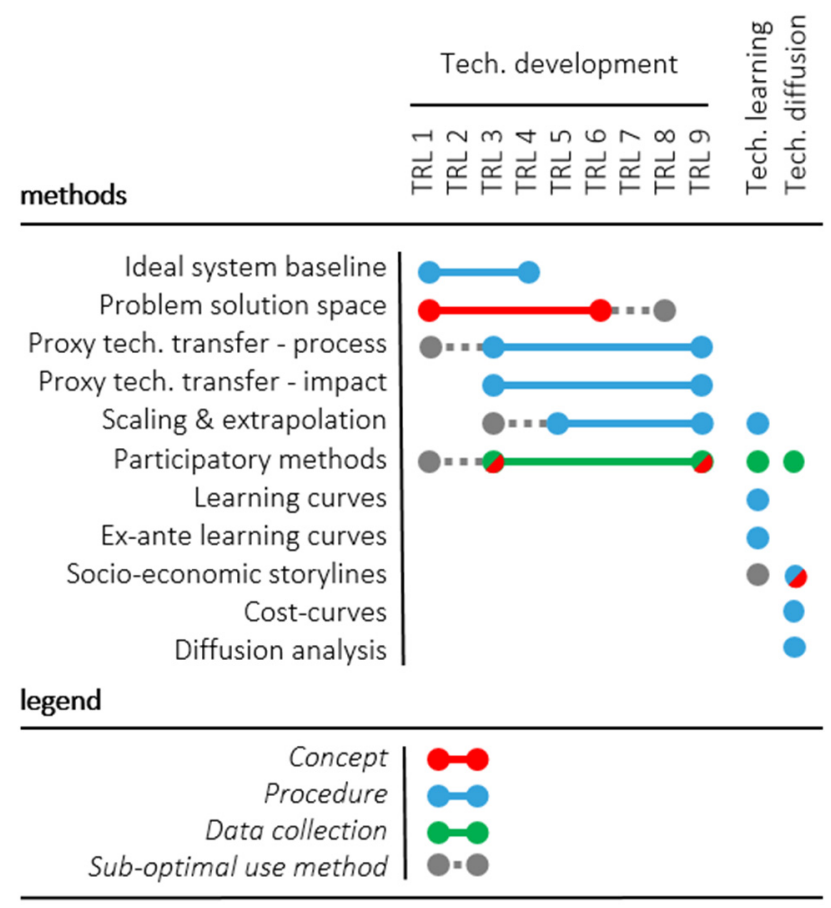

Figure 2. Methods to assess evolutions of a technology at different maturity levels. Concepts: a way of thinking about what is possible and/or likely to happen. Procedures: technical and delimited set of actions. Data collection: gathering the required input data. Sub-optimal use method: it is possible to use the methods at this technology readiness level (TRL), but other methods can also be more appropriate.

\subsection{General Observations}

In this section, some issues that apply to ex-ante LCA in general are highlighted. The first three topics can be linked to the ambiguity of expectations on future evolutions. After a brief discussion on the added layer of uncertainty in ex-ante studies, the implications of defining the functional equivalence of a system under study and an incumbent technology are discussed. The third topic is how the development of scenarios can be used to deal with this uncertainty. Additionally, the fourth topic has a different focus and discusses the implication of selecting different system models.

\subsubsection{Uncertainty}

Ex-ante LCA deals with unknown future situations where predictions and estimations result in additional uncertainties. They need to be added to the uncertainties of a conventional ex-post LCA, such as those related to the unresolved problems in LCA, as listed by Reap et al. [79]. Other sources of uncertainty can emanate from a lack of information on novel processes, spill-overs from other industries, socio-economic evolutions, etc. In short: the fact that possible future states are explored, inherently adds a layer of uncertainty. Therefore, the output of an ex-ante LCA should not be interpreted as an absolute result but rather as an indication of what might happen [75]. In a more general context of futures research, Glenn put forward that such research should not be judged by whether these forecasts were right or wrong, but by their ability to help decision makers create policy now [80]. How this uncertain context is usually dealt with in ex-ante LCA can be linked to two philosophies about the strictness of delimiting the functionality of a system under study [75]. First and most commonly applied, is an engineering relationships approach with a certain degree of predictability assumed to exist during the process of technology development. The main goal is the assessment of how a predefined targeted functionality can be reached. In this approach, the existence of a specific development path is assumed, excluding the uncertainties related to the choice for other possible paths. For example, Manda et al. assessed innovative materials and finishing techniques with antibacterial T-shirts as the clearly targeted output [59]. Secondly, as an alternative, an exploratory 
approach aims at collecting and analysing contextual background information in order to define plausible scenarios. In this case, defining the properties of the final output is part of the research. More types of uncertainty are accounted for, potentially resulting in a larger discrepancy between results. Nonetheless, valuable insights may be gained on research trajectories that were not envisaged from the start. So far, this approach is basically only mentioned as a research opportunity; it is not often applied. Nevertheless, it can prove to be very relevant in the case of low TRLs, among others, to explore different pathways for industrial symbiosis. Indeed, design-based decisions may result in by-products with unexpected properties, thus affecting potential interaction with other industries.

\subsubsection{Functional Equivalence}

The concept of a functional unit is central in LCA, as it forms the basis for a meaningful comparison across alternative production systems or services. However, it is not straightforward to identify all relevant properties of emerging technologies at an industrial scale based on lab information. At the same time, these properties influence the identification of the best available technology providing a similar function to that of the emerging one, which can be defined as the incumbent technologies or the reference system. For emerging technologies to be able to compete with an incumbent technology, a substantial improvement in performance is indispensable [4]. Such an innovation can lead to the creation of unique properties of the emerging technology, which makes it hard to select the incumbent technology with which to compare. It is likely that in many cases a one-by-one substitution is not realistic. Healy et al. [51] compared several processes to produce single-walled carbon nanotubes on a mass base, without specifying any application nor required function. They state that it is unlikely that these materials will be directly substitutable in any application and suggest that future research is needed, which may significantly alter the results. Jeswiet and Hauschild [5] state that new products become more and more complex, with increasing functionality as a result. Sometimes there is even a shift in functionality compared to previous generations of a product. This evolution hinders a straightforward comparison of products. An additional challenge is that, during the process of technology development, the initially targeted function can evolve, which in turn affects the incumbent technology that is being compared. Villares et al. [75] suggest that synergies should be explored for metal recovery from e-waste with existing treatment technologies, resulting in a system that may require different feedstock materials and in- and outputs with different properties. This is a valid approach to maximise the environmental performance, but the fact that for each change in final product properties an alternative incumbent technology needs to be identified, is clearly a drawback.

When future states are compared, the same reasoning applies to mature technologies as well, which in turn can affect the selection of the incumbent technology or reference system. Even though less radical changes can be expected in the case of mature technologies, they do still evolve over time. This can result in just an increase of their overall efficiency, but a more fundamental change in functionality is possible too. For example, a smart phone cannot be directly compared to a traditional cell phone [43]. Similar to the discussion of Section 3.2.2, both an engineering and an explorative approach can be applied to identify the incumbent technology. However, Arvidson et al. [7] state that the imagination of the analyst is a limiting factor, leading to the selection of an incumbent technology that seems plausible in the current situation.

\subsubsection{Scenario Building}

To deal with uncertainties and issues on identifying the functional equivalence between technologies and production systems, scenarios are indispensable in ex-ante LCA. Many authors even state they should be included by definition (see Section 2.1). Again, different interpretations of the concept 'scenario' appear in the literature. The SETAC-Europe LCA Working Group 'Scenario Development in LCA' interpretation has been followed in this study, which states that most definitions include three basic elements: the definition of alternative future circumstances, the path from the present to the future and the inclusion of uncertainty about the future [81]. Different approaches have 
been observed to build scenarios that can be classified based on their conceptual strategy and on the type of variables included. Pesonen et al. [81] define two basic strategies: what-if scenarios and cornerstone scenarios. The first type is closely related to the engineering approach described in the previous section, as it compares two or more options in a well-known situation. Typically, changes in efficiencies or yields are assessed $[39,47,58,59]$. This approach is useful to identify hotspots for improvement, but it is unlikely that radical new insights will be gained. The second type, the cornerstone scenarios, goes further than comparing pre-set alternatives. It combines several divergent options to get an overall idea of how the system under study and its context might evolve over time; so, it actually resembles the exploratory approach. Such scenarios can suggest potential directions for future developments and often take a much broader socio-economic context into account. Spielmann et al. [29] used a formative scenario analysis (FSA) to develop cornerstone scenarios, including socio-economic key impact variables such as technological potential, operation conditions, lifestyle patterns and transport policy. Walser et al. [27] included variables focusing on technological development and trends in environmental awareness. A second aspect on constructing scenarios relates to the type of included variables [8]. Endogenous (or internal) variables are related to aspects within the system boundaries of the system under study. Examples are: efficiencies in energy and material use, valorisation of by-products, cumulative production or installed production capacity. Exogenous (or external) variables cannot be changed by technology developers, yet such variables can affect future developments to a great extent. Examples are: socio-economic trends and user preferences that can affect the acceptance of a new technology and consequently the speed and depth of the market penetration.

A distinction between these two types of variables is rarely mentioned explicitly in the literature, although the choice for one of them can affect the interpretation of the results. Rubin et al. [8] illustrate this with learning curves of energy technologies and their effect on policy incentives. Technological learning can be linked to the endogenous variables' cumulative output or installed capacity. A technology may improve through learning-by-doing as an increase in output can yield the opportunity to make the production process more efficient. So from this perspective, policy decisions should encourage the early adoption of the technology to reduce costs and environmental impacts. Technological learning can also be related to time. In this case, time represents an exogenous variable, assuming a technology will improve at a constant rate, independently of its deployment. In such a scenario, the incentive is to postpone the adoption of an emerging technology and install it at a lower cost in the future.

\subsubsection{System Models}

The rationale of the system model that links all processes in the foreground system depends on the goal and scope definition of a study and determines how the underlying logic of cause-effect relationships is modelled [22,82]. The choice for a specific system model is in most cases independent from the three technology-related aspects of the proposed framework. Yet, some modelling approaches touch on parts of it, such as an analysis of potential technology diffusion, for example. Therefore, a brief overview of the properties of the most commonly applied system models is provided in this section (more info can be found in $[21,83,84]$ ). Also, links with the three technology-related aspects presented in the following sections are highlighted.

In the literature, a distinction is usually made between an attributional and a consequential modelling approach. A major difference between them is that attributional LCA aims at describing the environmentally relevant flows within the chosen temporal window, while consequential LCA attempts to estimate how flows to and from the environment will change as a result of several possible decisions [22]. But in relation to the ex-ante LCA case studies, this can be further subdivided into three relevant system models $[83,85]$. First the attributional modelling approach includes all activities of a supply chain and basically all studies follow this approach.

Second there is the heuristic consequential modelling approach (h-CLCA). It is best known in the form of the four-step procedure of Weidema et al. [81] which describes how to identify the long-term 
marginal suppliers in perfectly elastic markets. A few studies apply this approach $[13,24,44]$. Also, the industry cost-curve approach applied by Katelhön et al. [55] strongly resembles the general principles of the work of Weidema et al. [84].

And finally, the equilibrium model-based consequential modelling approach (eq-CLCA) builds on consumer utility maximisation, producer profit maximisation and market equilibrium [86]. The equilibrium is maintained through changes in the price for a commodity, while the impact of a change in price on the market flows is quantified by the price elasticity [87]. In contrast to heuristic consequential LCA, not only can the activities that will be affected by a change in demand be identified, but also the market penetration after introducing a technology to the market. For example, Menten et al. [11] assessed the effect of introducing a biomass-to-liquids technology to the French energy system for a period from 2007 to 2030. A regional, technology-explicit, competitive partial equilibrium model was used. It included the energy, transport and (parts of) the agricultural sector. Technological improvements were considered as a constant improvement of the system efficiencies over time. This study integrated technological learning (see Section 3.3), technology diffusion (see Section 3.4) and a change-oriented modelling approach, based on price elasticities of supply and demand.

\subsection{Technology Development}

In this section, different techniques are discussed that can be used to upscale an emerging technology to a potential installation on an industrial scale. Per technique, the range of relevant TRLs is presented, as well as their categorisation as concept, procedure and technique for data collection (see Figure 2 as well).

\subsubsection{Ideal System Baseline (ISB)}

What and how. Every study starts from a basic hypothesis, idea or principle based on a quantifiable relationship. Chemical conversions can be examined by stochiometric or physicochemical models, energy requirements by thermodynamics, etc. So even before the draft of a first proof-of-concept at lab scale, it is possible to explore the theoretical potential of a new technology and to evaluate its environmental performance. This potential represents the ideal system, with the highest yields and efficiencies, so the corresponding environmental impact can be considered as the optimal baseline. The ideal system baseline approach is very suitable for the lower segment of the TRL scale, starting from level 1.

Evaluation. The relevance of the ideal system baseline approach consists mainly of being able to provide an initial indication of the environmental profile, even before lab tests are started. This way it can be used as a tool for an explorative approach. Of course, there is a very high level of uncertainty in the outcome, since practical feasibility and unexpected trade-offs have not yet been considered. Additionally, there is an inverse relationship between the level of detail (and therefore the amount of computational work) in predictive modelling and the uncertainty, yet this is, to date, not quantified. As an example, chemical innovations can be modelled by density functional theory (DFT), which is very computationally intensive and therefore used for molecular scale interactions only. Molecular dynamics, using force field calculations, should be used for higher scale predictions (to several thousands of molecules), yet they are less accurate. Moving to higher scales, thermodynamics should be combined with kinetic experiments to make process predictions. This includes potential losses by heat and mass transfer limitations or another that can be modelled, increasing the predictive accuracy but also the study intensity. In the literature, the ideal system baseline approach is also used as a procedure to be complemented with other methods. Tecchio et al. [71] have estimated the theoretical optimum for bio-based polybutylene succinate production by using a stoichiometric baseline. The data obtained are then used as input for further calculations to estimate a more realistic situation on an industrial scale (see Section 3.3.4). Piccinno et al. [63] on the other hand start from a catalytic reaction for heated liquid phase batch reactions. They link the separate chemical steps to similar processes on an industrial scale, making it possible to estimate the environmental profile on an industrial scale (see 
Section 3.3.3). The ideal system baseline approach is also used to set a range of values in sensitivity analysis, i.e., to define yields, efficiency, etc., $[67,76]$.

\subsubsection{Problem Solution Space (PSP)}

What and how. This concept starts from an ill-defined problem definition and explores possible applications of the system under study [75]. Its main purpose is searching for interesting opportunities and analysing unexpected functionalities during the early development, rather than working towards a clear target. This is a design approach that is recognised as the co-evolution of problem-solution space (or problem-solving space) [88]. In contrast to an engineering approach, the concept of the problem solution space requires much more creativity to identify unconventional opportunities and forces the practitioner to accept incompleteness, vagueness and ambiguity [89]. In fact, this concept can be applied during the entire process of technology development, though it is particularly relevant for low TRLs that explore many different pathways at low cost.

Evaluation. The main benefit is that opportunities that were not envisaged from the start are not neglected throughout the development process. However, expert judgement is essential in combination with the ability to imagine what is possible and to look beyond current practice. Despite being identified as a promising concept, the problem solution space has only seen very limited applications to date. Villares et al. [75] introduce this idea from a conceptual point of view without applying it; they link it to an exploratory approach. In a less extreme way, this concept is taken into account by Blok et al. [43] to define functionalities of emerging technologies, and by Wender et al. [76] to combine stakeholder opinions with direct research efforts.

\subsubsection{Proxy Technology Transfer-Process $\left(\mathrm{PTT}_{\mathrm{p}}\right)$}

What and how. Technologies under development rarely rely completely on new processes. Instead they are often a novel application of existing processing techniques or, at least, they show strong similarities. A process-based proxy technology transfer is a procedure to scale up technology from lab to industrial scale, starting from the inventory of existing production processes but with novel techniques replacing existing ones. Input and output can be computed based on estimates of efficiencies, yields and material flows. For example, the conversion from batch processes on a lab scale to continuous processes on an industrial scale can be estimated based on existing continuous production lines. This approach usually starts from lab experiments (TRL 3), but it is possible to start from the input of an ideal system baseline approach as well. This was demonstrated by Piccinno et al. [63], who included an extensive inventory of relevant proxy processes for continuous production starting from heated liquid phase batch reactions on a lab scale.

Evaluation. The advantage of the process-based proxy technology transfer is that lab scale information can be enriched with data on relevant production techniques on an industrial scale when it comes to highlighting the hotspots for improvement and to estimating the final production system. On the other hand, such an engineering approach is relying heavily on the knowledge of current practice, so some less obvious opportunities might be overlooked. Villares et al. [74,75] link lab tests on metal recovery from e-waste using bioleaching to state-of-play processes of the mining industry to extract metals from low grade ores. They conclude that the environmental impact when upscaling from lab to full scale will reduce by a factor ranging from two to ten depending on the considered impact category. Nonetheless, the impact of this innovative system will remain three orders of magnitude higher compared to a mature pyrometallurgical system. A similar approach is applied by Simon et al. [70] studying nanofibers for lithium iron phosphate cathode applications. They conclude that the emerging system has a considerably greater environmental impact compared to the current practice. Both studies focus on direct scaling of the processes, without making additional improvements or taking opportunities for industrial symbiosis into account. Muñoz et al. [24] apply the process-based proxy technology transfer in an assessment of solar-assisted thermal energy recovery from wastewater. They find that the emerging technology will outperform the current practice from both an environmental 
and a financial point of view. The difference with the work of Villares et al. [74,75] and Simon et al. [70] is that the thermal energy recovery technology actually is a combination of two emerging technologies with a higher readiness level. Therefore, more data are available and multiple optimisation rounds already have been run through, resulting in a better environmental performance that can even compete with the incumbent alternative.

\subsubsection{Proxy Technology Transfer-Impact $\left(\mathrm{PTT}_{\mathrm{i}}\right)$}

What and how. An alternative way to include information of existing but similar technologies is to focus on their environmental impact instead. Tecchio et al. [71] propose a procedure, shown in Figure 3, to estimate the environmental impact on an industrial scale by interpolating between the environmental impact on a lab scale (worst case) and the ideal system baseline (best case). For a mature technology, it should be possible to compute the environmental impact on a lab and an industrial scale, as well as the theoretical impact of the thermodynamic ideal situation. For the emerging technology, only data on the lab scale and a theoretical optimum are available. The relationship between the three data points is transferred from the mature to the emerging technology to estimate the impact on an industrial scale. A similar range of TRLs can be addressed, as in the case of the process-based proxy technology transfer.

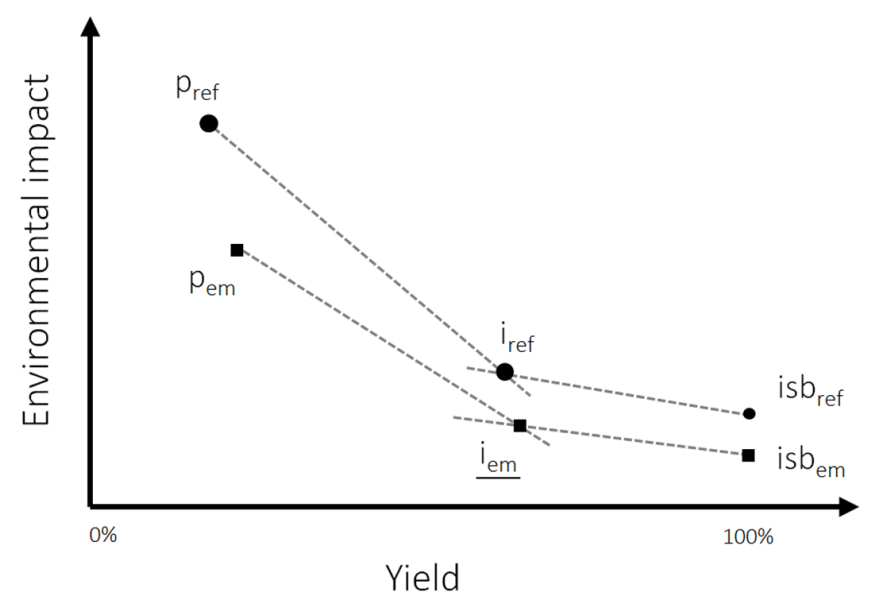

Figure 3. Impact based proxy technology transfer. Interpolation between the environmental impact on a lab scale $p_{\mathrm{em}}$ and the ideal system baseline $i_{\mathrm{s}} \mathrm{e}_{\mathrm{em}}$ to estimate the industrial scale $\mathrm{i}_{\mathrm{em}}$. Interpolation relationship is derived from a similar but mature reference technology. $p_{x}=$ pilot scale, $i_{x}=$ industrial scale, is $b_{x}=$ ideal system baseline, ref = reference technology, em = emerging technology (figure based on Tecchio et al. [71]).

Evaluation. This procedure can be considered as a black box approach, which has both pros and cons. A first advantage is the limited need for input data and different assumptions to get an idea of the full potential of an emerging technology, even without knowing how this can be achieved. A second advantage is that in the process of comparing to a mature technology that went through multiple optimisation cycles, technological learning is also accounted for in the final estimations for the emerging technology on an industrial scale, albeit indirectly. Yet, even though estimated impact might lie in a realistic range, it is impossible to identify hotspots for improvement. Also, the relationships used for interpolating strongly depend on the selected impact category. Apart from the work of Tecchio et al. [71], only a few other studies have included a similar approach. Caduff et al. [36] developed a process-based scaling model for heat production from biomass and heat humps and they compared these results to an impact-based scaling model for some impact categories. They noted a clear correlation between both scaling principles in the case of heat pumps, a poor correlation for pellet furnaces and no correlation at all for log furnaces. So it seems that the impact-based proxy technology transfer can be relevant for a first screening, although its final output should be interpreted with care. 


\subsubsection{Scaling and Extrapolation (S\&E)}

What and how. One of the most applied procedures is scaling and extrapolating from a lab scale to an industrial scale, based on a chosen ratio and assuming a certain degree of predictability. A scaling relationship can be defined for an entire installation or for its individual components separately. Scaling and extrapolation can be used both for modelling technology development and for technological learning. In the latter case, the focus is more on economies of scale (e.g., larger plant sizes [90]) and size of products (e.g., larger wind turbines [35]). Scaling mature technologies is more straightforward as there is a lower degree of freedom to modify the design. Also, there is sufficient information available on the current production process. In contrast to the assessment of emerging technologies, results can now be validated based on empirical observations as well.

Evaluation. The use of scaling and extrapolation comes in many different forms. The simplest approach is to scale linearly from a lab scale to an industrial scale, yielding identical impact per unit of output. This system-wide linear scaling is applied regularly $[24,48,57,64,69]$, although little insight can be gained with it. More relevant is the inclusion of small non-linear scaling effects, obtained by estimating changes of a limited set of relevant variables such as efficiencies, yields, etc., [39,51,56,63]. Defining separate scaling factors for individual components and/or processes enables the determination of the optimal size when a product or a production system is to be upscaled. Caduff et al. [35,36] did this based on empirical power laws for windmills and heating devices, making a distinction between size-dependent (scaled) and size-independent (unscaled) flows. Nordelöf et al. [37,38] scaled all parts of an automotive power electronic inverter unit linearly, yet with a different slope per part.

\subsubsection{Participatory Methods (PM)}

What and how. Participatory methods seek the insights and opinions of experts and stakeholders. The underlying philosophy is that the future is too complex to be analysed with rational models only, while expert judgements may rely on intuition and visioning as well [91]. Input can come from a single expert or a group of experts. In the latter case, assessment techniques range from structured to subjective judgement techniques. For example, the Delphi method is a structured communication technique enabling a group of experts to reach consensus on an interactive way. Focus groups on the other hand usually aim at an open discussion among experts and stakeholders [80]. In ex-ante LCA, participatory methods are mostly used as a way to collect data. To a lesser extent they occur in the development of cornerstone scenarios that take into account possible socio-economic trends.

Evaluation. The main advantage of data collection with participatory methods is that it is a relatively easy and straightforward approach. In complex situations with a high level of uncertainty, it can even be the only way to collect relevant information. A disadvantage may be that the experience gained by the experts is closely connected to current practice, which may not always result in representative information for future situations. Participatory methods require creativity and an uninhibited vision on what might be possible. A second downside is that it is very hard to validate results if they are based on expert opinions. Additionally, since every opinion involves value choices, it is almost impossible to derive completely neutral and objective data. Nonetheless almost all reviewed case studies rely on expert judgement to some extent, but mostly without accounting for the corresponding uncertainties.

\subsection{Technological Learning}

This section will present techniques to model continuous improvements of mature technologies. Both scaling and extrapolation and participatory methods are applicable in this context as well, but their evaluation will not be dealt with (see Figure 2 and Section 3.3).

\subsubsection{Learning Curves (LC)}

What and how. Once a technology is operational on an industrial scale, experience is gained on the current practice. This experience can be used to optimise the system, usually from a cost perspective. 
The two most important aspects in this case are learning-by-doing and learning-by-researching. The basic technological learning model was first introduced by Wright in 1936 [92], who observed that each time the cumulative production of airplanes had doubled, the cost per unit had dropped with a fixed rate. More generally, the cost of a technology $C$ at time $t$ can be described as an exponential function involving the initial cost $C_{0}$, the cumulative production $x$ at time 0 and $t$ and an empirically observed learning parameter $b$, as shown in Equation (1) [42]. In later research, two-factor learning curves were introduced, including both learning-by-doing and learning-by-researching [30]. Rubin et al. [8] and Jamasb [30] provide a comprehensive overview of the current state-of-the-art. Learning curves typically model cost reductions, but they are relevant from an environmental point of view as well. Cost savings can indeed be caused by a fall in labour costs as well as by a more efficient use of energy and materials.

$$
C_{t}=C_{0}\left(\frac{x_{t}}{x_{0}}\right)^{b}
$$

Evaluation. The main benefit of incorporating learning curves in LCA is the possibility to account for the empirical evidence of technological improvements. This is especially relevant for the exploration of future states in the background system, which mainly consists of mature technologies. Beltran et al. [12] link an integrated assessment model to the ecoinvent database in order to compute a consistent ex-ante LCA background database; it is illustrated by a case study on passenger vehicles. Global single-factor learning rates are derived from the Integrated Model to Assess the Global Environment (IMAGE). In this study, technological changes are largely governed by endogenous mechanisms based on cumulative capacity. In addition, some exogenous factors are accounted for too, such as spill-over effects from other industries. Both technology and market changes for the electricity production technologies are considered, with the latter as the most influential parameter regarding the total change of impacts. The importance of market changes over technological improvements is amplified for more ambitious climate scenarios that are consistent with the two-degree goal of the United Nations [93], since the use of renewable energy technologies is primarily affected. Bauer et al. [41] included learning effects exogenously, as a constant improvement rate per year. Learning curves are models that usually focus on cost reduction. However, Louwen et al. [94] estimated empirical learning rates for photovoltaic panels based on cumulative capacity for costs, cumulative energy demand (CED) and global warming potential (GWP). From this empirical evidence, it was observed that cost reductions can be linked to reductions in environmental impact. This means that cost reductions may not only be achieved through increasing labour efficiency, but by material and energy efficiency improvements as well. A disadvantage of learning curves is that they are used to analyse empirical data and therefore are ex-post by definition. Another drawback is that they have high data requirements, which may complicate the implementation of two-factor learning curves [30]. Learning curves also reflect aggregated observed trends, so it is difficult to trace the causality that triggered the technological improvements [42].

\subsubsection{Ex-Ante Learning Curves (Ex-Ante LC)}

What and how. The disadvantage of learning curves being ex-post by definition can be partially eliminated by extrapolating them based on the expected changes in production volumes or installed capacity. In this way, endogenous factors of technological learning can be linked to exogenous socio-economic trends that affect the demand and the corresponding market penetration for the technology under study. However, the remarks as for scaling and extrapolation apply here as well, namely that ex-ante learning curves start from the assumption that observed learning rates can be representative for future situations. This issue could be overcome by adapting the empirical learning rates, for example based on expert opinions that account for expected trends.

Evaluation. Ex-ante learning curves allow for applying analytic quantitative models in a much broader explorative context. For example, they can be based on certain cornerstone scenarios to estimate future production volumes or the installed capacity. Only a few examples could be found 
in the literature. De Wit et al. [95] explored the potential for future cost reduction due to learning in dedicated wood production systems, by a breakdown of costs based on current practice (bottom-up) and experience curves based on long-term evolutions (top-down). These derived learning curves are combined with demand projections to estimate at what point minimum costs could be reached. Similar to the general learning curves, cost reduction may lead to improvement of the environmental performance as well. But how cost-based learning curves can be translated to environmental learning curves remains a challenge.

\subsubsection{Socio-Economic Storylines (SES)}

What and how. Socio-economic storylines aim at shaping a broader context by exploring different economic, technological, environmental and social realities [96]. Such exogenous variables can have a significant effect on the development, acceptance and diffusion of a new technology. Socio-economic storylines are generally a result of qualitative participatory methods such as stakeholder workshops and interviews. They are relevant in complex situations where the level of uncertainty is high or where the information cannot be entirely quantified [96]. In a conventional LCA, this type of scenario typically falls outside the direct system boundaries of a production system, yet in an ex-ante context, this information should not be neglected.

Evaluation. The inclusion of socio-economic storylines is useful if major societal changes are expected and especially in the case of strongly interlinked systems. Currently, such storylines are mostly applied to include scenarios for future energy systems $[41,46,50,72]$ and sometimes only relate to the input of a specific part of the study. For example, by including the cornerstone scenarios as developed for the IEA World Energy Outlook [97]. Beltran et al. [12] go a step further: they link an integrated assessment model to ecoinvent and apply consistent scenarios at the level of an entire background database. In their study, such an approach delivered promising results, but at the same time, it was shown that the approach can be very data intensive, which undermines its general applicability.

\subsection{Technology Diffusion}

Once a technology is ready to enter the market, its market penetration over time is usually estimated with the help of economic models. Nonetheless, from an environmental point of view, the analysis of technology diffusion is highly relevant as well. Changes in the composition of market mixes can have a greater effect on the total environmental impact, compared to the effects of technological learning. In this section, techniques to model technology diffusion will be presented. Both participatory methods and socio-economic storylines are applicable in this context as well, but their evaluation will not be dealt with here (see Figure 2 and Sections 3.3 and 3.4).

\subsubsection{Diffusion Analysis (DA)}

What and how. In recent decades, many models have been developed to estimate the market diffusion after the introduction of a new (or improved) technology. Sharp and Miller [98] distinguish two types of approaches, namely macro- and micro-level models. The Bass model, a well-known example of a macro-level model in use since the 1960s, has gradually been enriched over the years. This model describes the interaction between current and potential adopters of a new product [9]. Such models estimate the aggregated overall market penetration and the corresponding timeframe, in the tacit assumption that the population is homogeneous [98]. For the assessment of the adoption behaviour of individuals in a heterogeneous population, micro-level models such as agent-based modelling are more appropriate. Such models define relatively simple decision rules for individual actors to simulate complex situations.

Evaluation. Both the micro- and macro-level models have already proved their worth to assess market penetration; still, they have barely been implemented in an LCA context. They are typically used as a commercial tool to estimate the market penetration of a new technology or product in combination with the effect of variables such as advertisements. But they are not yet used for computing future 
market mixes in environmental studies. So far, diffusion analysis is only mentioned as an interesting research opportunity. It has not been tested in a case study yet [43,76].

\subsubsection{Cost-Curves (CC)}

What and how. Cost-curves are a micro-economic technique to plot the production capacity and the costs of an entire industry. Typically, cost-curves are used to set prices, depending on the production capacities of the various producers, the production cost per producer and the total demand for a product [99]. Besides, cost-curves can be used to model the substitution of competing technologies as well [55] and also to evaluate strategies to reduce emissions relative to a reference scenario, including the costs and benefits [60]. Incorporating cost-curves in ex-ante LCA make it possible to identify environmental impacts of the market mix for a certain product by linking data from individual technologies to their total expected sales volume.

Evaluation. Cost-curves allow estimating market mixes based on costs and the expected market situation. The main advantage of this procedure is that, in a reasonably straightforward way, market mechanisms can be accounted for if one has to estimate the market penetration in the long run. However, if the aim is to go beyond the use of cost-curves as a price setting tool, environmental aspects have to be taken into account from the start of a study. This can be difficult for technologies that have just entered the market and can even become a real challenge in the case of emerging technologies. Katelhön et al. [55] state that, for all assessed values of the sales volume, the introduction of oxygen depolarised cathodes for chlor-alkali electrolysis to the German market will result in an environmental benefit. However, an identical increase in production will result in a much greater reduction of the global warming potential for low aggregated sales volumes compared to high aggregated ones. Based on a combination of a marginal abatement cost curve analysis and LCA, O'Brien et al. [60] assessed strategies to reduce agricultural greenhouse gas emissions for Ireland. They concluded that measures to increase efficiency were cost-effective, measures on land-use change were cost-neutral and that technological interventions were cost prohibitive in most cases.

\section{Discussion and Conclusion}

There is increasing attention being given to ex-ante LCA, mainly addressing emerging technologies. However, this trend is accompanied by a proliferation of definitions, concepts and methods. Therefore, the purpose of this study is to clarify terminology and to structure current practice by introducing a general framework that fits recent research efforts. Unlike previous work on ex-ante LCA, the proposed framework includes the entire technology life cycle, from the early design phase up to continuous improvements of mature technologies, including their market penetration. This approach not only facilitates the comparison of different studies, but it also allows for a categorisation and evaluation of the applied techniques, concepts and procedures in order to assess technology development, technological learning and technology diffusion. Additionally, it can assist in the determination of eventual knowledge gaps or research opportunities.

It is generally acknowledged in the literature that integrating LCA early-on in the technology developing process can steer design choices towards a maximisation of the final environmental performance of a technology. However, to date, only a few studies focus on integrating environmental aspects at low TRLs. The ideal system baseline approach is the only observed procedure that is applicable from the formulation of the first ideas on, albeit with only a few applications. There is room for improving this approach to include modelling techniques that estimate more realistic process conditions, by combining for instance molecular dynamics with macro-scale kinetics, and mass and heat transfer calculations. Yet, this requires further study, and the link between various techniques used and reduced uncertainty is unclear to date. Additionally, the explorative approach as proposed by Villares et al. [75] looks promising for examining possibilities for low TRLs as well, at least from a conceptual point of view, but it lacks implementation. Most studies focus on very narrowly defined system boundaries to exclude uncertain aspect, but as a result, unexpected yet promising 
research opportunities might be overlooked. Relevant in this context is the story-telling approach of Tan et al. [17], who included multiple research iterations of a single technology: they carried out two simulated and two experimental stages. The storyline provides insight into how practical problems were tackled in each iteration from the very start and how this affected further research efforts.

Many research efforts focus on learning curves of cost reductions, and some of them have already observed a correlation between cost reduction and improvement of the environmental performance of a technology. Nonetheless, a research opportunity is to structurally incorporate technological learning in ex-ante LCA in order to investigate the system wide environmental consequences of technological developments. It is essential to model the total observed cost reduction of a technology, as a result of the combined learning effect related to the direct inputs to a technology such as materials, energy and labour [98]. Such a component learning approach is relevant to identifying the learning effect of each input, which is useful for complementing the cost estimates with environmental impact estimations. For example, Bergesen and Suh [42] decompose technological learning into subcomponents and then identify changes in (1) the quantities of direct inputs required, (2) the direct value added, (3) the quantities of intermediate inputs required by products upstream in the supply chain and (4) the supply value added. The first and the third points are especially of interest for the assessment of the environmental performance. To streamline such research efforts, Huenteler et al. [101] distinguish between two categories of products that define the learning potential. For mass-produced products and commodities (e.g., PV panels), early product innovations are followed relatively quickly by a surge of process innovation with learning-by-doing as the main driver. Complex products and systems on the other hand (e.g., windmills) have a longer initial period with competing product architectures, while afterwards the focus of innovation shifts to different parts of the product, rather than from the product to process innovations. In this case, learning-by-researching is the main driver. Both Bergesen and Suh [42] and Huenteler et al. [101] focus on decomposing technological learning, which is essential to assess environmental issues.

The lack of transparency is a general issue in many LCAs, but it is even more pronounced in an ex-ante context. Considering future situations, many assumptions are needed to explore potential developments. One would expect that all assumptions made are clearly described and justified. Yet in many studies, not all information on how a technology was scaled up is disclosed, for reasons of confidentiality $[17,27,33]$. The same remark applies when expert judgements are used. These can be a valuable input, yet without being able to discuss or validate such information a study becomes more or less a black box with little added value. Understanding the insights gained during technology development and validating the applied methods and concepts are often more important than obtaining the final numeric results. For example, disclosing information about (partially) failed research iterations instead of presenting only the final results would certainly be useful in the field of ex-ante LCA, as demonstrated by Tan et al. [17]. There is a clear need for transparent data presentation, which is definitely possible as, for example, is shown by Muñoz et al. [24], Caduff et al. [35,36] and Villares et al. [74,75].

Three other research opportunities deserve to be mentioned here: the combination of different aspects of the framework, a diversification of studied topics and the incorporation of innovative technology into the corresponding business models. Up to now, few studies have combined changes in both the foreground and the background system or have explored potential feedback mechanisms. The authors also do not know of any ex-ante LCA study that covers all three aspects of the proposed framework, namely technology development, technological learning and technology diffusion. Regarding the assessed topics, the technology development of energy systems, electric vehicles and nanotechnology is often assessed, just as technological learning is in energy systems. An opportunity would be to broaden the field of application of ex-ante LCA. Finally, in this work the focus is on technological evolutions over time. Therefore, a last research opportunity would be to dig deeper into how such technology is expected to be used in the future. As a result of the growing attention for the circular economy concept, alternative business models relying on sale-and-take-back, 
lease and pay-per-use contracts could be explored in combination with the expected technological evolutions [102].

To conclude, ex-ante LCA has the potential to influence technology development from the very start and to lead research efforts towards maximisation of the final environmental performance. Also, ex-ante LCA should not be limited to technologies under development alone, as mature technologies may still improve over time as well, sometimes with changing market shares as well. Additionally, aiming to include ex-ante LCA at lower TRLs can provide interesting design opportunities. This review has tried to present an overview of the different aspects of ex-ante LCA by introducing a generic framework and has linked this framework to an overview of practical concepts and procedures. However, further research will have to focus on refining these methods and procedures, with special attention for validation and transparent communication of the results and the underlying assumptions.

Author Contributions: M.B. conceived the general framework, with equal support to the study design of all co-authors. M.B., A.A., P.B., K.B., S.V.P. made the data collection, the analysis of them and the writing of the paper.

Funding: This research did not receive a specific grant from funding agencies in the public, commercial, or not-for-profit sectors but was made possible thanks to their research appointment at the University of Antwerp and the Flemish Institute for Technological Research.

Acknowledgments: Thanks to Koen Breemersch for providing insightful and useful comments on draft versions of this manuscript. This work was supported by the University of Antwerp and the Flemish Institute for Technological Research (VITO). The authors also acknowledge anonymous reviewers for the constructive suggestions and the stimulating discussion.

Conflicts of Interest: The authors declare no conflict of interest.

\section{Abbreviations}

$\begin{array}{ll}\text { LCA } & \text { life cycle assessment } \\ \text { LCIA } & \text { life cycle impact assessment } \\ \text { LCI } & \text { life cycle inventory } \\ \text { ALCA } & \text { attributional LCA } \\ \text { h-CLCA } & \text { heuristic consequential LCA } \\ \text { eq-CLCA } & \text { equilibrium model-based consequential LCA } \\ \text { CED } & \text { cumulative energy demand } \\ \text { GWP } & \text { global warming potential } \\ \text { FSA } & \text { formative scenario analysis } \\ \text { TRL } & \text { technology readiness level } \\ \text { MRL } & \text { manufacturing readiness level } \\ \text { ISB } & \text { ideal system baseline } \\ \text { PSP } & \text { problem solution space } \\ \text { PTT } & \text { proxy technology transfer - process } \\ \text { PTT } & \text { proxy technology transfer - impact } \\ \text { S\&E } & \text { scaling and extrapolation } \\ \text { PM } & \text { participatory methods } \\ \text { LC } & \text { learning curves } \\ \text { SES } & \text { socio-economic storylines } \\ \text { DA } & \text { diffusion analysis } \\ \text { CC } & \text { cost-curves } \\ & \end{array}$

\section{References}

1. European Commission-Joint Research Centre-Institute for Environment and Sustainability. ILCD Handbook: General Guide to Life Cycle Assessment-Detailed Guidance, 1st ed.; Publications Office of the European Union: Luxembourg, 2010; ISBN 9789279190926.

2. Hellweg, S.; Canals, L.M.I. Emerging approaches, challenges and opportunities in life cycle assessment. Science 2014, 344, 1109-1113. [CrossRef] [PubMed] 
3. Frischknecht, R.; Büsser, S.; Krewitt, W. Environmental assessment of future technologies: How to trim LCA to fit this goal? Int. J. Life Cycle Assess. 2009, 14, 584-588. [CrossRef]

4. Cucurachi, S.; Van Der Giesen, C.; Guinée, J. Ex-ante LCA of Emerging Technologies. Procedia CIRP 2018, 69, 463-468. [CrossRef]

5. Jeswiet, J.; Hauschild, M. EcoDesign and future environmental impacts. Mater. Des. 2005, 26, 629-634. [CrossRef]

6. Collingridge, D. The Social Control of Technology; Frances Pinter: London, UK, 1980; ISBN 0903804727.

7. Arvidsson, R.; Tillman, A.-M.; Sandén, B.A.; Janssen, M.; Nordelöf, A.; Kushnir, D.; Molander, S. Environmental assessment of emerging technologies: Recommendations for prospective LCA. J. Ind. Ecol. 2017, 22, 1286-1294. [CrossRef]

8. Rubin, E.S.; Azevedo, I.M.L.; Jaramillo, P.; Yeh, S. A review of learning rates for electricity supply technologies. Energy Policy 2015, 86, 198-218. [CrossRef]

9. Bass, F.M. Comments on "A New Product Growth for Model Consumer Durables The Bass Model". Manag. Sci. 2004, 50, 1833-1840. [CrossRef]

10. Green, R.; Agarwal, R.; Logue, D. Innovation. In International Encyclopedia of the Social E Behavioral Sciences; Wright, J.D., Ed.; Elsevier: Amsterdam, The Netherlands, 2015; pp. 145-151.

11. Menten, F.; Tchung-Ming, S.; Lorne, D.; Bouvart, F. Lessons from the use of a long-term energy model for consequential life cycle assessment: The BTL case. Renew. Sustain. Energy Rev. 2015, 43, 942-960. [CrossRef]

12. Mendoza Beltran, A.; Cox, B.; Mutel, C.; van Vuuren, D.P.; Font Vivanco, D.; Deetman, S.; Edelenbosch, O.Y.; Guinée, J.; Tukker, A. When the Background Matters: Using Scenarios from Integrated Assessment Models in Prospective Life Cycle Assessment. J. Ind. Ecol. 2018, 1-16. [CrossRef]

13. Vandepaer, L.; Treyer, K.; Mutel, C.; Bauer, C.; Amor, B. The integration of long-term marginal electricity supply mixes in the ecoinvent consequential database version 3.4 and examination of modeling choices. Int. J. Life Cycle Assess. 2018. [CrossRef]

14. International Organisation for Standardization. ISO 14040-Environmental Management-Life Cycle Assessment-Principles and Framework; International Organisation for Standardization: Geneva, Switzerland, 2006.

15. International Organisation for Standardization. ISO 14044-Environmental Management-Life Cycle Assessment_-Requirements and Guidelines; International Organisation for Standardization: Geneva, Switserland, 2006.

16. Kendall, A. Time-adjusted global warming potentials for LCA and carbon footprints. Int. J. Life Cycle Assess. 2012, 17, 1042-1049. [CrossRef]

17. Tan, L.; Mandley, S.J.; Peijnenburg, W.; Waaijers-van der Loop, S.L.; Giesen, D.; Legradi, J.B.; Shen, L. Combining ex-ante LCA and EHS screening to assist green design: A case study of cellulose nanocrystal foam. J. Clean. Prod. 2018, 178, 494-506. [CrossRef]

18. Breton, C.; Blanchet, P.; Amor, B.; Beauregard, R.; Chang, W.-S. Assessing the Climate Change Impacts of Biogenic Carbon in Buildings: A Critical Review of Two Main Dynamic Approaches. Sustainability 2018, 10, 2020. [CrossRef]

19. De Rosa, M.; Pizzol, M.; Schmidt, J. How methodological choices affect LCA climate impact results: The case of structural timber. Int. J. Life Cycle Assess. 2018, 23, 147-158. [CrossRef]

20. Guinée, J.B.; Cucurachi, S.; Henriksson, P.J.G.; Heijungs, R. Digesting the alphabet soup of LCA. Int. J. Life Cycle Assess. 2018, 23, 1507-1511. [CrossRef]

21. Zamagni, A.; Guinée, J.; Heijungs, R.; Masoni, P.; Raggi, A. Lights and shadows in consequential LCA. Int. J. Life Cycle Assess. 2012, 17, 904-918. [CrossRef]

22. Curran, M.; Mann, M.; Norris, G. The international workshop on electricity data for life cycle inventories. J. Clean. Prod. 2005, 13, 853-862. [CrossRef]

23. Chen, I.C.; Fukushima, Y.; Kikuchi, Y.; Hirao, M. A graphical representation for consequential life cycle assessment of future technologies. Part 1: Methodological framework. Int. J. Life Cycle Assess. 2012, 17, 119-125. [CrossRef]

24. Muñoz, I.; Portillo, F.; Rosiek, S.; Batlles, F.J.; Martínez-Del-Río, J.; Acasuso, I.; Piergrossi, V.; De Sanctis, M.; Chimienti, S.; Di Iaconi, C. Prospective environmental and economic assessment of solar-assisted thermal energy recovery from wastewater through a sequencing batch biofilter granular reactor. J. Clean. Prod. 2019, 212, 1300-1309. [CrossRef]

25. Heijungs, R.; Huppes, G.; Guinée, J. A Scientific Framework for LCA; Institute of Environmental Sciences, Leiden University: Leiden, The Netherlands, 2009; p. 37. 
26. Wender, B.A.; Foley, R.W.; Hottle, T.A.; Sadowski, J.; Prado-Lopez, V.; Eisenberg, D.A.; Laurin, L.; Seager, T.P. Anticipatory life-cycle assessment for responsible research and innovation. J. Responsible Innov. 2014, 1, 200-207. [CrossRef]

27. Walser, T.; Demou, E.; Lang, D.J.; Hellweg, S. Prospective environmental life cycle assessment of nanosilver T-shirts. Environ. Sci. Technol. 2011, 45, 4570-4578. [CrossRef] [PubMed]

28. Miller, S.A.; Keoleian, G.A. Framework for analyzing transformative technologies in life cycle assessment. Environ. Sci. Technol. 2015, 49, 3067-3075. [CrossRef] [PubMed]

29. Spielmann, M.; Scholz, R.W.; Tietje, O.; Haan, P. de Scenario Modelling in Prospective LCA of Transport Systems. Int. J. Life Cycle Assess. 2005, 10, 325-335. [CrossRef]

30. Jamasb, T. Technical Change Theory and Learning Curves: Patterns of Progress in Electricity Generation Technologies. Energy J. 2007, 28, 51-71. [CrossRef]

31. Stahl, B.C. What Does the Future Hold? A Critical View of Emerging Information and Communication Technologies and Their Social Consequences. In Researching the Future in Information Systems; Springer: Berlin/Heidelberg, Germany, 2011; pp. 59-76.

32. Rotolo, D.; Hicks, D.; Martin, B.R. What is an emerging technology? Res. Policy 2015, 44, $1827-1843$. [CrossRef]

33. Gavankar, S.; Suh, S.; Keller, A.A. The Role of Scale and Technology Maturity in Life Cycle Assessment of Emerging Technologies: A Case Study on Carbon Nanotubes. J. Ind. Ecol. 2015, 19, 51-60. [CrossRef]

34. Fernandez, J.A. Contextual Role of TRLs and MRLs in Technology Management; Sandia National Laboratories: Albuquerque, NM, USA, 2010.

35. Caduff, M.; Huijbregts, M.A.J.; Althaus, H.J.; Koehler, A.; Hellweg, S. Wind power electricity: The bigger the turbine, the greener the electricity? Environ. Sci. Technol. 2012, 46, 4725-4733. [CrossRef]

36. Caduff, M.; Huijbregts, M.A.J.; Koehler, A.; Althaus, H.J.; Hellweg, S. Scaling Relationships in Life Cycle Assessment: The Case of Heat Production from Biomass and Heat Pumps. J. Ind. Ecol. 2014, 18, 393-406. [CrossRef]

37. Nordelöf, A.; Alatalo, M.; Söderman, M.L. A scalable life cycle inventory of an automotive power electronic inverter unit-Part I: Design and composition. Int. J. Life Cycle Assess. 2019, 24, 78-92. [CrossRef]

38. Nordelöf, A. A scalable life cycle inventory of an automotive power electronic inverter unit-Part II: Manufacturing processes. Int. J. Life Cycle Assess. 2019, 24, 694-711. [CrossRef]

39. Arvidsson, R.; Molander, S. Prospective Life Cycle Assessment of Epitaxial Graphene Production at Different Manufacturing Scales and Maturity. J. Ind. Ecol. 2017, 21, 1153-1164. [CrossRef]

40. Aryapratama, R.; Janssen, M. Prospective life cycle assessment of bio-based adipic acid production from forest residues. J. Clean. Prod. 2017, 164, 434-443. [CrossRef]

41. Bauer, C.; Hofer, J.; Althaus, H.J.; Del Duce, A.; Simons, A. The environmental performance of current and future passenger vehicles: Life Cycle Assessment based on a novel scenario analysis framework. Appl. Energy 2015, 157, 871-883. [CrossRef]

42. Bergesen, J.D.; Suh, S. A framework for technological learning in the supply chain: A case study on CdTe photovoltaics. Appl. Energy 2016, 169, 721-728. [CrossRef]

43. Blok, K.; Huijbregts, M.; Patel, M.K.; Hertwich, E.; Hauschild, M.; Sellke, P.; Antunes, P.; Hellweg, S.; Mays, C.; Ciroth, A.; et al. Handbook on a Novel Methodology for the Sustainability Impact Assessment of New Technologies; Utrecht University Repository: Utrecht, The Netherlands, 2013.

44. Buyle, M.; Pizzol, M.; Audenaert, A. Identifying marginal suppliers of construction materials: Consistent modeling and sensitivity analysis on a Belgian case. Int. J. Life Cycle Assess. 2018, 23, 1624-1640. [CrossRef]

45. Chen, I.C.; Fukushima, Y.; Kikuchi, Y.; Hirao, M. A graphical representation for consequential life cycle assessment of future technologies-Part 2: Two case studies on choice of technologies and evaluation of technology improvements. Int. J. Life Cycle Assess. 2012, 17, 270-276. [CrossRef]

46. Cox, B.; Mutel, C.L.; Bauer, C.; Mendoza Beltran, A.; Van Vuuren, D.P. Uncertain environmental footprint of current and future battery electric vehicles. Environ. Sci. Technol. 2018, 52, 4989-4995. [CrossRef] [PubMed]

47. Delgado-Aguilar, M.; Tarrés, Q.; Pèlach, M.À.; Mutjé, P.; Fullana-i-Palmer, P. Are cellulose nanofibers a solution for a more circular economy of paper products? Environ. Sci. Technol. 2015, 49, 12206-12213. [CrossRef] 
48. Dick, M.; Dewulf, W.; Birkhofer, H.; Duflou, J. Estimating the environmental impacts of similar products. In Proceedings of the DS 32: Proceedings of DESIGN 2004, the 8th International Design Conference, Dubrovnik, Croatia, 18-21 May 2004; pp. 1-6.

49. Garcia-Gusano, D.; Garrain, D.; Dufour, J. Prospective life cycle assessment of the Spanish electricity production. Renew. Sustain. Energy Rev. 2017, 75, 21-34. [CrossRef]

50. Gibon, T.; Wood, R.; Arvesen, A.; Bergesen, J.D.; Suh, S.; Hertwich, E.G. A Methodology for Integrated, Multiregional Life Cycle Assessment Scenarios under Large-Scale Technological Change. Environ. Sci. Technol. 2015, 49, 11218-11226. [CrossRef]

51. Healy, M.L.; Dahlben, L.J.; Isaacs, J.A. Environmental assessment of single-walled carbon nanotube processes. J. Ind. Ecol. 2008, 12, 376-393. [CrossRef]

52. Hospido, A.; Davis, J.; Berlin, J.; Sonesson, U. A review of methodological issues affecting LCA of novel food products. Int. J. Life Cycle Assess. 2010, 15, 44-52. [CrossRef]

53. Hung, C.R.; Ellingsen, L.A.W.; Majeau-Bettez, G. LiSET: A Framework for Early-Stage Life Cycle Screening of Emerging Technologies. J. Ind. Ecol. 2018, 1-12. [CrossRef]

54. Janssen, M.; Tillman, A.M.; Cannella, D.; Jørgensen, H. Influence of high gravity process conditions on the environmental impact of ethanol production from wheat straw. Bioresour. Technol. 2014, 173, 148-158. [CrossRef] [PubMed]

55. Katelhön, A.; Von Der Assen, N.; Suh, S.; Jung, J.; Bardow, A. Industry-Cost-Curve Approach for Modeling the Environmental Impact of Introducing New Technologies in Life Cycle Assessment. Environ. Sci. Technol. 2015, 49, 7543-7551. [CrossRef] [PubMed]

56. Kushnir, D.; Sandén, B.A. Energy requirements of carbon nanoparticle production. J. Ind. Ecol. 2008, 12, 360-375. [CrossRef]

57. Liptow, C.; Tillman, A.M.; Janssen, M. Life cycle assessment of biomass-based ethylene production in Sweden-Is gasification or fermentation the environmentally preferable route? Int. J. Life Cycle Assess. 2015, 20, 632-644. [CrossRef]

58. Manda, B.M.K.; Worrell, E.; Patel, M.K. Innovative membrane filtration system for micropollutant removal from drinking water-Prospective environmental LCA and its integration in business decisions. J. Clean. Prod. 2014, 72, 153-166. [CrossRef]

59. Manda, B.M.K.; Worrell, E.; Patel, M.K. Prospective life cycle assessment of an antibacterial T-shirt and supporting business decisions to create value. Resour. Conserv. Recycl. 2015, 103, 47-57. [CrossRef]

60. O’Brien, D.; Shalloo, L.; Crosson, P.; Donnellan, T.; Farrelly, N.; Finnan, J.; Hanrahan, K.; Lalor, S.; Lanigan, G.; Thorne, F.; et al. An evaluation of the effect of greenhouse gas accounting methods on a marginal abatement cost curve for Irish agricultural greenhouse gas emissions. Environ. Sci. Policy 2014, 39, 107-118. [CrossRef]

61. Patel, A.D.; Meesters, K.; Den Uil, H.; De Jong, E.; Blok, K.; Patel, M.K. Sustainability assessment of novel chemical processes at early stage: Application to biobased processes. Energy Environ. Sci. 2012, 5, 8430-8444. [CrossRef]

62. Pehnt, M. Dynamic life cycle assessment (LCA) of renewable energy technologies. Renew. Energy 2006, 31, 55-71. [CrossRef]

63. Piccinno, F.; Hischier, R.; Seeger, S.; Som, C. From laboratory to industrial scale: A scale-up framework for chemical processes in life cycle assessment studies. J. Clean. Prod. 2016, 135, 1085-1097. [CrossRef]

64. Pini, M.; Cedillo González, E.; Neri, P.; Siligardi, C.; Ferrari, A. Assessment of Environmental Performance of $\mathrm{TiO}_{2}$ Nanoparticles Coated Self-Cleaning Float Glass. Coatings 2017, 7, 8. [CrossRef]

65. Ravikumar, D.; Seager, T.P.; Cucurachi, S.; Prado, V.; Mutel, C. Novel Method of Sensitivity Analysis Improves the Prioritization of Research in Anticipatory Life Cycle Assessment of Emerging Technologies. Environ. Sci. Technol. 2018, 52, 6534-6543. [CrossRef]

66. Ravikumar, D.; Sinha, P.; Seager, T.P.; Fraser, M.P. An anticipatory approach to quantify energetics of recycling CdTe photovoltaic systems. Prog. Photovolt. Res. Appl. 2016, 24, 735-746. [CrossRef]

67. Roes, A.L.; Patel, M.K. Ex-ante environmental assessments of novel technologies-improved caprolactam catalysis and hydrogen storage. J. Clean. Prod. 2011, 19, 1659-1667. [CrossRef]

68. Shibasaki, M.; Fischer, M.; Barthel, L. Effects on Life Cycle Assessment-Scale Up of Processes. In Proceedings of the 14th CIRP Conference on Life Cycle Engineering, Waseda University, Tokyo, Japan, 11-13 June 2007; pp. 377-381. 
69. Shibasaki, M.; Warburg, N.; Eyerer, P. Upscaling effect and Life Cycle Assessment. In Proceedings of the 13th CIRP International Conference on Life Cycle Engineering, Leuven, Belgium, 31 May-2 June 2006; pp. 61-64.

70. Simon, B.; Bachtin, K.; Kiliç, A.; Amor, B.; Weil, M. Proposal of a framework for scale-up life cycle inventory: A case of nanofibers for lithium iron phosphate cathode applications. Integr. Environ. Assess. Manag. 2016, 12, 465-477. [CrossRef]

71. Tecchio, P.; Freni, P.; De Benedetti, B.; Fenouillot, F. Ex-ante Life Cycle Assessment approach developed for a case study on bio-based polybutylene succinate. J. Clean. Prod. 2016, 112, 316-325. [CrossRef]

72. Van der Voet, E.; Van Oers, L.; Verboon, M.; Kuipers, K. Environmental implications of future demand scenarios for metals: Methodology and application to the case of seven major metals. J. Ind. Ecol. 2019, 23, 141-155. [CrossRef]

73. Vandepaer, L.; Bauer, C.; Treyer, K.; Mutel, C.L. Marginal electricity supply mixes and their integration in version 3.4 of the ecoinvent database. In Proceedings of the 23rd LCA Case Study Symposium, Barcelona, Spain, 27-28 November 2017; pp. 1-18.

74. Villares, M.; Işildar, A.; Mendoza Beltran, A.; Guinee, J. Applying an ex-ante life cycle perspective to metal recovery from e-waste using bioleaching. J. Clean. Prod. 2016, 129, 315-328. [CrossRef]

75. Villares, M.; Işıldar, A.; van der Giesen, C.; Guinée, J. Does ex ante application enhance the usefulness of LCA? A case study on an emerging technology for metal recovery from e-waste. Int. J. Life Cycle Assess. 2017, 22, 1618-1633. [CrossRef]

76. Wender, B.A.; Foley, R.W.; Prado-Lopez, V.; Ravikumar, D.; Eisenberg, D.A.; Hottle, T.A.; Sadowski, J.; Flanagan, W.P.; Fisher, A.; Laurin, L.; et al. Illustrating anticipatory life cycle assessment for emerging photovoltaic technologies. Environ. Sci. Technol. 2014, 48, 10531-10538. [CrossRef] [PubMed]

77. Yao, Y.; Graziano, D.J.; Riddle, M.; Cresko, J.; Masanet, E. Prospective energy analysis of emerging technology options for the united states ethylene industry. Ind. Eng. Chem. Res. 2016, 55, 3493-3505. [CrossRef]

78. Zimmermann, B.M.; Dura, H.; Baumann, M.J.; Weil, M.R. Prospective time-resolved LCA of fully electric supercap vehicles in Germany. Integr. Environ. Assess. Manag. 2015, 11, 425-434. [CrossRef] [PubMed]

79. Reap, J.; Roman, F.; Duncan, S.; Bras, B. A survey of unresolved problems in life cycle assessment. Part 1: Goal and scope and inventory analysis. Int. J. Life Cycle Assess. 2008, 13, 290-300. [CrossRef]

80. Glenn, J.C. Introduction to the Futures Research Methodology Series; United Nations University: Washington, DC, USA, 1994.

81. Pesonen, H.L.; Ekvall, T.; Fleischer, G.; Huppes, G.; Jahn, C.; Klos, Z.S.; Rebitzer, G.; Sonnemann, G.W.; Tintinelli, A.; Weidema, B.P.; et al. Framework for scenario development in LCA. Int. J. Life Cycle Assess. 2000, 5, 21-30. [CrossRef]

82. Weidema, B.P. UMIP 2003 Method. Environmental News No. 74 2004. In Geographical, Technological and Temporal Delimitation in LCA; Danish Environmental Protection Agency: Kopenhagen, Denmark, 2004.

83. Earles, J.M.; Halog, A. Consequential life cycle assessment: A review. Int. J. Life Cycle Assess. 2011, 16, 445-453. [CrossRef]

84. Weidema, B.P.; Ekvall, T.; Heijungs, R. Guidelines for Application of Deepened and Broadened LCA-Deliverable D18 of Work Package 5 of the CALCAS Project; CALCAS-Co-ordination Action for Innovation in Life-Cycle Analysis for Sustainability: Colorado Spring, CO, USA, 2009; p. 49.

85. Buyle, M. Towards a Structured Consequential Modelling Approach for the Construction Sector: The Belgian Case: A Fairy Tale on Methodological Choices in LCA. Ph.D. Thesis, University of Antwerp, Antwerpen, Belgium, 2018.

86. Yang, Y.; Heijungs, R. On the use of different models for consequential life cycle assessment. Int. J. Life Cycle Assess. 2018, 23, 751-758. [CrossRef]

87. Brandao, M.; Martin, M.; Cowie, A.; Hamelin, L.; Zamagni, A. Consequential Life Cycle Assessment: What, How, and Why? Encycl. Sustain. Technol. 2017, 277-284. [CrossRef]

88. Dorst, K.; Cross, N. Creativity in the design process: Co-evolution of problem-solution. Des. Stud. 2001, 22, 425-437. [CrossRef]

89. Haupt, G. Learning from experts: Fostering extended thinking in the early phases of the design process. Int. J. Technol. Des. Educ. 2015, 25, 483-520. [CrossRef]

90. Hetherington, A.C.; Borrion, A.L.; Griffiths, O.G.; McManus, M.C. Use of LCA as a development tool within early research: Challenges and issues across different sectors. Int. J. Life Cycle Assess. 2014, 19, 130-143. [CrossRef] 
91. Weidema, B.P. Environmental Project No. 863. In Market Information in Life Cycle Assessment; Miljøstyrelsen: Copenhagen, Denmark, 2003.

92. Wright, T.P. Factors Affecting the Cost of Airplanes. J. Aeronaut. Sci. 1936, 3, 122-128. [CrossRef]

93. UNFCCC. The Cancun agreements. United Nations Framework Convention on Climate Change: Cancun Climate Change Conference. Available online: https://unfccc.int/event/cancun-climate-change-conferencenovember-2010-meetings-page (accessed on 9 May 2019).

94. Louwen, A.; Van Sark, W.G.J.H.M.; Faaij, A.P.C.; Schropp, R.E.I. Re-assessment of net energy production and greenhouse gas emissions avoidance after 40 years of photovoltaics development. Nat. Commun. 2016, 7, 1-9. [CrossRef] [PubMed]

95. De Wit, M.; Junginger, M.; Faaij, A. Learning in dedicated wood production systems: Past trends, future outlook and implications for bioenergy. Renew. Sustain. Energy Rev. 2013, 19, 417-432. [CrossRef]

96. Fortes, P.; Alvarenga, A.; Seixas, J.; Rodrigues, S. Long-term energy scenarios: Bridging the gap between socio-economic storylines and energy modeling. Technol. Forecast. Soc. Chang. 2015, 91, 161-178. [CrossRef]

97. IEA. World Energy Outlook 2016; IEA: Paris, France, 2016.

98. Sharp, B.E.; Miller, S.A. Potential for Integrating Diffusion of Innovation Principles into Life Cycle Assessment of Emerging Technologies. Environ. Sci. Technol. 2016, 50, 2771-2781. [CrossRef]

99. Tholana, T.; Musingwini, C.; Njowa, G. An algorithm to construct industry cost curves used in analysing cash cost performance of operations for selected minerals in South Africa. J. South. Afr. Inst. Min. Metall. 2013, 113, 473-484.

100. Ferioli, F.; Schoots, K.; van der Zwaan, B.C.C. Use and limitations of learning curves for energy technology policy: A component-learning hypothesis. Energy Policy 2009, 37, 2525-2535. [CrossRef]

101. Huenteler, J.; Schmidt, T.S.; Ossenbrink, J.; Hoffmann, V.H. Technology life-cycles in the energy sector-Technological characteristics and the role of deployment for innovation. Technol. Forecast. Soc. Chang. 2016, 104, 102-121. [CrossRef]

102. Ellen MacArthur Foundation. Delivering the Circular Economy: A Toolkit for Policymakers; Ellen MacArthur Foundation: London, UK, 2015. 